The contribution of medicine to civilisation aided by the other sciences is great. A healthy body means a healthy mind, and such minds are less likely to cause internal or external strife. A day may be conceived when physical warfare will give place to warfare of the intellect. There will be no jealousy, and superiority or inferiority complexes will cease to exist. Man will live by making every part of the world healthy and habitable by im. proved methods of hygiene, thereby minimising the need for the control of population, the overgrowth of which has been considered to be, to a great extent, responsible for many wars of the past. Further, a day may come when the war mentality of individual statesmen, which may lead to war psychosis among the people, will be analysed and corrected by the psychiatrist and the psycho. logist.

Although the mechanism of life cannot be explained by the physies and chemistry of to-day, some of it may be explained by ultra-physicochemical laws that may be discovered in the future : yet even then one may not be able to say wherein enters the breath of life.

\title{
British Industries Fair
}

\section{SCIENTIFIC Exhibits}

$\mathrm{T}^{\mathrm{H}}$ HE British Industries Fair, 1936, which opened on February 17 , is not only the largest trade fair in the world, but it is also this year larger than it has ever been since it was first held in 1915 . Its object is to assemble before the greatest number of potential buyers, both from Great Britain and from overseas, the greatest possible concentration of British manufactures. Only goods manufactured or produced within the British Empire are permitted to be displayed, and no exhibitor may exhibit articles other than those of his own manufacture. Thus the Fair forms a visible microcosm, showing the variety, range and character of the goods manufactured or produced within the British Empire. It would, of course, be an impossible task to attempt to review the twenty-four miles of exhibits that constitute the combined stand frontage at London (including Olympia and the White City) and Birmingham. All that can usefully be attempted here is to direct attention to some features, selected somewhat arbitrarily, of the scientific exhibits at Olympia.

The most striking of these exhibits is that of the scientific instrument manufacturers, who have this year excelled their previous efforts to produce, by a combined or, rather, grouped exhibit, a massed impression of the great variety and range of their products. Truth to tell, it could be more impressive still, for, although most of the leading scientific instrument manufacturers are well represented, there se obvious and notable absentees. It must be allowed that this is in part due to the fact that many of the scientific exhibits, more particularly of electrical instruments used largely in industry, are to be seen at Birmingham, where they are more appropriately shown in the company of the engineering exhibits. Moreover, it is probable that some scientific instrument manufacturers, especially those whose products appeal more particularly to the research worker or to the educationist, deem the annual exhibition of the Physical Society a more suitable occasion for the display of their latest products. But the British Industries Fair is of the utmost national importance; it attracts visitors from almost every quarter of the world; and such visitors cannot help but take away with them a vivid, and perhaps lasting, impression of what British industry in general and, what is more to our present point, the British scientific instrument industry in particular, is like, regarded as a whole. It would be a pity if, from lack of support from some important firms in the industry, the impression should be gathered that the industry is less comprehensive, less varied in the range of its products and less remarkable in its achievements than in fact it is.

Nevertheless, those who have been responsible for the organisation of the grouped exhibit of scientific instruments at this Fair are to be warmly congratı1. lated on a notable and effective display. This year it occupies the record space of 5,840 square feet, the central and dominating feature being a scale model of the Eddystone Lighthouse which has been erected by Chance Brothers and Co., Ltd., of Birmingham. This firm shows, besides the usual mouldings for lenses and prisms, sample plates of various types of optical glass, including didymium glass, and a set of colour filters. In another case it is exhibiting specimens of laboratory ware, micro cover-glass and four shades of Crooke's glass.

Projection apparatus is well to the fore. Ross, Ltd. show the latest appliances for cine-photography, both for the silent and the sound film, as do Soho, Ltd. and Kalee, Ltd. A new feature in connexion with such apparatus is the exhibit of heat-resisting glass for the condensers, towards the satisfactory production of which a good deal of recent research has been directed. The firm of Charles Baker shows a new type of episcope, with a $f / 4$ anastigmat lens, the body incorporating a new system of ventilation, so that it remains relatively cool even when the apparatus is run for long periods. This firm also exhibits a new production, the 'universal lantern', again embodying a special system of cooling the body; and the 'ultra pack illuminator', which has been designed to take the place of the older form of vertical illuminator and hitherto has been made only abroad.

Barr and Stroud, Ltd. show a full range of varied types of binoculars. They reserve the exhibition of their navigational range finders for the Shipping Exhibition which is held later in the year. Their binoculars include the central focusing and separate focusing types, prismatic binoculars of extra wide angle, and a series of prismatic monoculars. They should be congratulated also on issuing, among their literature, an admirably lucid and concise little booklet, entitled "Choosing a Binocular", which will prove most useful to the potential purchaser, whatever make of binocular he may eventually buy. 
Ross, Ltd. also exhibit on their stand a wide range of their binoculars, including those of extra wide angle and those of great light-gathering power. They show also a large number of types of their photographic lenses, fitted to various makes of camera, and exhibit several types of telescopes. Perhaps their most striking exhibit is a recent product, a massive epidiascope capable of projecting the image of an object $13 \mathrm{in}$. square. The illumination is derived from four 1,000-watt lamps, and a cooling fan, electrically driven, is incorporated.

Among the exhibits of R. and J. Beck, Ltd. are to be noticed many types of their microscopes, from the microscope for school use to that used for ad. vanced research. They include the angular microscope (an entirely new design), a combined binocular and monocular microscope, and the Wrighton metallurgical outfit, made to a specification prepared in the Research Department, Woolwich. Attention should also be directed to the projectograph exhibited by this firm, which has been designed to give a wellilluminated picture either by the shadowgraph method, showing the outline of an object, or by the opaque method, giving a view of the actual surface.

W. Watson and Sons, Ltd. exhibit, besides the usual range of their microscopes, several new products, including a machine for polishing metal specimens and useful for petrological work, and a profile-projecting apparatus. They show also a new camera, the Sayce-Watson camera, which depends fundamentally upon the use of standard $35 \mathrm{~mm}$. cinematograph film. It is designed to replace a variety of photographic equipment by one apparatus, in which the objects sought have been primarily economy, compactness and simplicity. Mention should also be made of the Watson-MeArthur microscope, a portable microscope having the minimum of movable parts, which was described in the Journal of the Royal Microscopical Society, January, 1934.

Tintometer, Ltd. show some new models of comparators for the testing of various media by means of colour matching, and new colorimeters are shown by Bellingham and Stanley, Ltd. W. F. Stanley and Co., Ltd. exhibit some interesting examples of planimeters, which are the first and only Britishmade planimeters, this type of instrument having been previously obtainable only from abroad. Two main types are shown, the sliding bar pattern and the radial pattern.

We have space only for brief mention of the chemical exhibits at Olympia. The theme of the main stand of the Imperial Chemical Industries, Ltd. is the technical service offered to their customers. They show a working exhibit of the water-treatment service and another concerning dyestuffs and drycleaning. The first of the 'Solacet' colours is shown. These have only just been introduced, and are the culmination of prolonged research on the problem of producing the perfect dyes for the direct dyeing of acetate silk. Monastral Fast Blue $B S$ is shown on the stand of the Association of British Chemical Manufacturers, and is claimed to be the chemical achievement of the year. It is the first blue pigment to have been discovered since ultramarine in 1826 . A simplified model of the Billingham coal-oil plant will arouse much interest and so will the sheets of the new plastic product, 'Perspex', shown on the stand of Mouldrite Limited, a subsidiary of Imperial Chemical Industries, Ltd. Among the other numerous and impressive chemical exhibits, mention may be made of the stands of Hopkin and Williams, Ltd. and the British Drug Houses, Ltd. The former exhibit phenyldi-iodarsine, the optical properties of which were found by Anderson and Payne (Nature, 133, 66 ; 1934) to render it a very valuable medium in the examination of precious stones by refractivity methods.

Lastly, bare mention may be made of the 'Vitan' lamp (a fused quartz mercury vapour lamp), of the highly refractory re-crystallised alumina ware, and of the fused silica and vitreosil ware to be seen on the stand of the Thermal Syndicate, Ltd.

Taken altogether, science shows up well at this Fair, and in particular do the exhibits make manifest the truth of the slogan printed over the combined exhibit of scientific instruments: "Science aids Industry".

\section{Educational Topics and Events}

Cambridge.-Dr. P. W. Richards, fellow of Trinity College, will deliver two lectures in the Department of Botany on March 6 and 13 at 5 p.m. on "The Tropical Rain Forest". The lectures will be based on Dr. Richards's work in Borneo, British Guiana and Southern Nigeria.

Sir William Pope and Prof. H. C. Gutteridge have been appointed delegates of the University to the tercentenary of the University of Utrecht to be held on June 22-24.

OxFord.-Dr. Edwin P. Hubble, astronomer at the Mount Wilson Observatory, has been appointed to deliver the Rhodes Memorial Lectures for the year 1936-37.

THE Le Play Society has arranged the following programme of visits to various European countries: Morocco, with Mr. W. Fogg (also a botanical group); a survey from north to south of Portugal, including Lisbon, with Dr. L. Dudley Stamp; Holland and its galleries, with Dr. G. Furlong; Glendalough, Co. Wicklow, a regional study, with Dr. D. K. Smee and Mr. T. W. Freeman; and the Cotswolds, a training course in field studies, with Miss C. A. Simpson. All these visits are open to lecturers, teachers, students and others who are interested in the studies undertaken. Further information can be obtained from Miss Margaret Tatton, The Le Play Society, 58 Gordon Square, London, W.C.1.

IN an address to the American Association for the Advancement of Science at its recent meeting in St. Louis, Dr. Oscar Riddle, of the Carnegie Institution of Washington, discussed the position of biology in American Schools. He stated that great numbers of high school and college students complete their school-days with their education incomplete in that it includes little or nothing of information about biological subjects. Apart from the danger, due to biological ignorance, of unintelligent pressure for retrograde points of view (as seen in the anti-evolution laws), there is the greater danger that scientific research may advance so rapidly in relation to the biological knowledge of the people in general, as to become quite out of touch with their daily life. It would be the greatest misfortune to science as well as to the populace were neglect of instruction in biological subjects in the schools to make scientific progress a sealed book to all but a few other than professional scientific workers. 